MedieKultur | Journal of media and communication research | ISSN 1901-9726

Book Review

\title{
David Gauntlett: \\ Making is connecting. The Social Meaning of creativity, from DIY and knitting to YouTube and Web 2.0. \\ Cambridge: Polity Press. 2011.
}

\section{Dagny Stuedahl}

MedieKultur 2013, 54, 203-205

Published by SMID | Society of Media researchers In Denmark | www.smid.dk The online version of this text can be found open access at www.mediekultur.dk

While media studies generally are concerned by the new forms of activism and democracy, use and citizenship that are traced back to media convergence, critical voices have raised to ask if these new forms also require that media studies start posing new questions (Hay and Couldry 2012). While media studies have been concerned with active reading and articulation practices related to media messages, it seems that the little, everyday, multiform making and productivity introduced by Cultural Studies in the 1960ties now is reintroduced. While the discourse on convergence culture, trans-media and creative industry may remind of the relation between media and making introduced then, it seems that todays departure point for assessing convergence culture requires a break with the media centric perspectives that have dominated media studies in the past Hay and Couldry argue.

David Gauntlett, professor of Media and Communications at University of Westminster, UK takes in his last book departure in exploring this break with the media centric view. His main argument is to understand peoples' everyday creativity as important to capture the shift in "how we deal with the world". For him, this shift is related to "people rejecting the given and making their world anew". Gauntlett points to the Web 2.0 and the powerful social dimensions that is established by people who collaboratively are writing and editing creative content online. The even more powerful dimension is meanwhile the leap to offline social politics, learning and identity shaping that people do - empowered by technology. By this, Gauntlett points to the resurgence of DIY (Do It Yourself) and the growing interest in craft activities as well as the Transition movement, where environmen- 
Book Review: Making is connecting. The Social Meaning of creativity, from DIY ...

tal concerns are related to finding new ways to re-use and recycle physical material. He is proposing to understand these phenomena that transgress the hand-made dimension of creativity and the political environmental activities related to issues of sustainability,

Gauntlett proposes with this book to understand Web 2.0 creativity in relation to the cultural and political processes that partly goes on online, but that is grounded in offline everyday activities. The argument is that Web 2.0 creativity best can be captured by studying the connection between online and offline, or virtual and real if you may. His suggested approach is to understand peoples making and doing as based on the integration of media as tools for creative productions and explorations instead of for plain reading and interpretations of messages. By this he is suggesting to focus on peoples activities of making as based in cultural and social values - and to understand media as scaffolding tools and spaces for communication related to these activities. By this, the book suggests to break with the media centric past by building on the affinity between communication and culture.

In addition to the argument on new media perspectives into understanding Web 2.0 creativity, Gauntlett also steers another reasoning in parallel, concerning the educational role of making and doing. This argument builds on that the "sit back and be told" culture of western educational systems of schooling and teaching is now beginning to be criticised from several angles, including teachers. The argument is that it seems to produce dropouts and for those students that manages to fulfil their schooling, it is not evident what kind of knowledge they in fact have gained during their school years and how relevant this is for the life outside the educational system. This critique is supported by critical pedagogy developed by educational thinkers such as John Dewey, Rudolph Steiner and Ivan Illich that call for a new approach to teaching and learning that include supportive and relevant social interactions between people. Many new teaching efforts include experimental and explorative learning that involves to put weight on hands-on approaches and that are highly based on awareness of the role of learning contexts. These critical approaches to learning challenge the test-based learning approaches stated by formal educational policy. Gauntlett points to how the DIY and making culture connected to the new forms of media use, in fact comes in serious conflict with the formal learning approaches in current educational systems.

Following this line of argument, Gauntlett introduces the reader to thinkers and theories related to understanding power relations in creativity and craft activities, to understand the motivational factors in subcultures such as punk DIY, but also in the current growing community of crafters that connects personal values and politics as embedded in their collective and creative activities. The digital creativity, which has concerned Gauntlett in earlier publications on methodological challenges related to the digital (such as Creative Explorations 2007) is also critically analysed in relation to the template based production of websites and stringent use of pre-produced social sites such as Facebook. Web 2.0 is not all rosy when it comes to individual freedom and creativity after all. Gauntlett discusses the ambivalences connected to freedom and quality of publication on for example YouTube. 
All in all it seems that his analysis easily can be attuned to Hay and Couldrys' argument stating that to understand the relation between media and making in the digital on a deeper level we need to study the limitations of creativity and sharing (Hay and Couldry 2011).

Gauntlett has with Making is Connecting started the exiting work to unpack peoples creativity with Web 2.0 technologies as being in relation to wider ongoing cultural processes. His proposal to focus on what people are making and doing and why they are doing it, do coincide with the renewed discussion of the relation between media studies and cultural studies. It could be said that several of the empirical examples he is using could be analysed deeper and on a more detailed level. Meanwhile the intention of the book to map out a new approach to understand media use as being based on creative making and collaborating is communicated. And the book gives a clear reference point for studies in media as well as learning sciences to point out how media builds only one piece of a whole of the sociocultural processes of mediation.

\section{References}

Hay, J. \& Couldry, N. (2011). Rethinking Convergence/Culture. Cultural Studies, 25: 4-5, 473-486.

Gauntlett, D. (2007). Creative Explorations: new approaches to identities and audiences. London: Routledge.

Dagny Stuedahl

Dr. polit, senior researcher

InterMedia

Department of Education

University of Oslo, Norway

dagny.stuedahl@intermedia.uio.no 